\title{
The National Water-Quality Assessment Program- Entering a new decade of investigations
}

In 2001, the U.S. Geological

Survey's National Water-Quality Assessment (NAWQA) Program begins its second decade of intensive water-quality assessments. NAWQA scientists will return to 14 major river-basin and aquifer systems that were assessed in the first decade; another two groups of 14 will be studied beginning in 2004 and 2007. In this second cycle of studies, NAWQA will build upon its initial assessments of water-quality conditions and will increase its investigation of long-term trends and the factors that affect water quality.

\section{Long-term mission and goals}

The NAWQA Program is a primary source for long-term, nationwide information on the quality of streams, ground water, and aquatic ecosystems. This information supports national, regional, State, and local decision making and policy formation for water-quality management. The goals of NAWQA are to assess the status and trends of national water quality and to understand the factors that affect it, thus, addressing the questions:

- What is the condition of our Nation's streams and ground water?

- How is water quality changing over time?

- How do natural features and human activities affect the quality of streams and ground water?

Major river basins and aquifers across the Nation define NAWQA "study units" (see maps). Within these areas, USGS scientists collect and analyze information on water chemistry, hydrology, land use, stream habitat, and aquatic life. Each study-unit assessment is an interdisciplinary and long-term evaluation of the total resource, rather than a short-term study of a specific geographic area or problem at a single point in time. NAWQA findings thereby describe the general health of water resources, as well as current and emerging water issues-information that is essential for developing practical management strategies for protecting and restoring water quality.

Because each study-unit assessment adheres to a national design and nationally consistent sampling and analytical methods, water-quality conditions in a specific locality or watershed can be compared to those in other geographic regions and at different periods of time. Collectively, the assessments advance an understanding of the quality of our Nation's waters and whether water quality is getting better or worse over time. Information at different scales helps to bridge local, State, regional, and national efforts to manage the Nation's water resources.

Although NAWQA is a comprehensive effort to assess the quality of streams and ground water, no single program can address or anticipate all water-resource issues that are nationally relevant. Only through collaboration with numerous government, research, and interest-group partners can we ensure that NAWQA information will meet the needs of local, State, regional, and national stakeholders. These partnerships are a vital element of the NAWQA design. Input from these partners has been critical as NAWQA moves into its second cycle of investigations, and has helped to define the key water-quality resource issues on which to focus.

"The NAWOA Program...[is] generating high quality data of direct benefit to State agencies. NAWOA has provided the model for how different programs should work together and benefit from each other's research."

-Robert Bode, New York State Department of Environmental Conservation, in U.S. Geological Survey Circular 1165

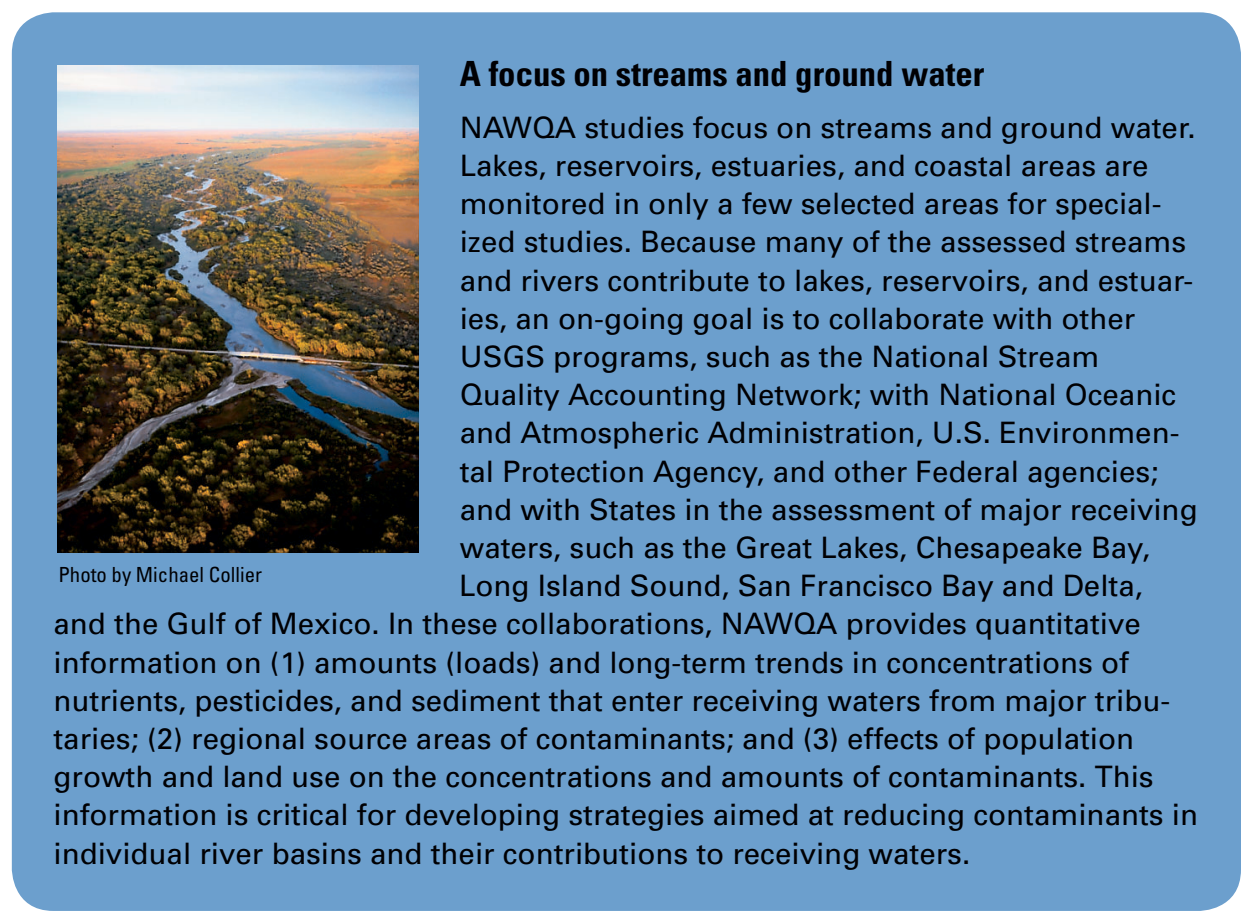




\section{Drinking Water-Characterizing source waters}

NAWQA studies are not designed to assess the quality of the Nation's drinking water, such as by monitoring water from taps. Rather, the studies characterize the quality of source waters and thereby complement drinking-water monitoring by Federal, State, and local programs, which focus primarily on post-treatment compliance monitoring. In the second cycle of studies, NAWQA will increase its emphasis on source-water assessments for critical surface- and ground-water supplies and will continue to collaborate with other agencies and organizations involved with managing and supplying drinking water.

Photo by Dennis A. Wentz

\section{Progress on Program goals}

During the first cycle of studies from 1991 to 2001, NAWQA made considerable progress toward its first goal of assessing current water-quality conditions in streams and ground water. Descriptions of local and national water-quality conditions are presented in hundreds of reports (http://water.usgs.gov/nawqa), and provide comparable information for streams and ground water throughout the Nation. In its second cycle, when most study units will be intensively reassessed (see maps), NAWQA will fill in geographic gaps, investigate selected new contaminants, and address the many complexities of contaminant occurrence, such as mixtures, degradation products, and seasonal variations in contaminant concentrations.

The NAWQA Program also progressed toward its second goal of assessing longterm trends. For example, long-term trends were demonstrated for persistent contaminants in sediment and fish, such as DDT, PCBs, and lead, as well as for other contaminants in those study units for which historical data were available. Most importantly, however, baseline conditions were established for comparison to future measurements and long-term monitoring was initiated in every study unit. The major thrust for evaluating trends will, therefore, occur in the second cycle when study units systematically are reassessed and an increasing number of stream and ground-water sampling sites will have had 10 years of consistent monitoring.

\section{Linking sources, transport, and effects}

The increased focus on understanding the factors that affect water quality will establish the links among sources of contaminants and other disturbances that degrade water quality, transport of contaminants through the hydrologic system, and the potential effects of contaminants and other water-quality disturbances on humans and aquatic ecosystems. This information will provide an improved scientific basis for decision makers to effectively implement water-quality management strategies in specific geographic areas, and to prioritize the multitude of decisions involving the increasing number of competing demands for safe drinking water, irrigation, aquatic ecosystem health, wetland protection, native and endangered species preservation, and recreation.

Sources-NAWQA studies relate water-quality conditions to natural and human-related sources of contaminants and land-use changes. Urbanization, agriculture, and other land uses can substantially affect sources of contaminants and the quality of water resources and aquatic ecosystems. Key questions include: What are the effects of urbanization on the quality of ground water and streams, and how does stream quality change as urban development intensifies? Does water quality deteriorate as residential land use spreads with growing population? What are the effects of agricultural practices, such as tillage methods, chemical use, and crop patterns, on the sources of contaminants to ground water and streams?

\section{Emerging contaminants-A modest expansion}

NAWQA studies focus on water-quality conditions with long-term national importance and for which there are well-established methods. Budget resources and technical feasibility limit expansion of NAWQA studies to include the dynamic and extensive number of emerging contaminants in our Nation's waters; however, there are incremental increases in the scope of contaminants for national assessment as important issues are identified and methods are developed. In addition, other USGS programs, such as the Toxic Substances Hydrology Program (http://water.usgs.gov/toxics), address the emerging contaminants issue.

In the second cycle of studies, NAWQA will initiate assessment of three main categories of contaminants not included in the national design for the first cycle: (1) selected new pesticides with high usage in agricultural and populated areas across the Nation, and pesticide degradation products; (2) indicators of waterborne diseases in streams and ground water that are sources of drinking water and in streams that are used for water-contact recreation; and (3) total mercury and methylmercury in streams that have the greatest potential for human exposure through the consumption of fish. 
"The NAWQA Program is essential to understanding the impact of land-use changes on the quality of water flowing to the Great Lakes...Findings are directly applicable to resource managers and planners and transferable throughout the Great Lakes Basin."

-Great Lakes Commission, composed of 8 states, in the Legislative and Appropriations Priorities for the 106th Congress

Transport-NAWQA studies assess the effects of management practices and natural factors, such as soils, geology, and hydrology, on the transport of contaminants. Even among similar land uses and sources of contamination, differences in natural factors can result in very different degrees of vulnerability to contamination and different rates at which improved management can lead to improved water quality. Key questions include: What factors control the transport of contaminants as they move from land to shallow ground water and underlying aquifers? What happens to these contaminants as they move from land to streams and then downstream to reservoirs and coastal waters? How do interactions between ground water and surface water affect the degree and timing of contamination in our water resources?

Effects - The NAWQA Program continues its efforts to better understand the effects of contaminants and habitat disturbance on stream ecosystems, and the potential importance of contaminants to humans through characterizing the quality of drinking water sources. Key questions include: What contaminants occur in aquifers and streams used for public and domestic supplies of drinking water? Are contaminants present at levels of concern for human health and aquatic ecosystems? Are aquatic organisms changing in diversity and abundance because of land-use changes, habitat alteration, and degradation of water quality? What are the effects of nutrient enrichment on stream ecosystems?

\section{"The St. Croix National Scenic River-} way (NSR) was established in 1968 under the National Wild and Scenic Rivers Act. In the early 1990's, continued development and usage of the St. Croix River concerned water resource managers about the impact on water quality. Research from the NAWQA Program provided evidence that nutrient loading from the tributaries was increasing the rate of eutrophication in Lake St. Croix, a sink of the St. Croix River Basin. In response to these threats, a cooperative agreement was signed in 1993 by the National Park Service, the Minnesota Department of Natural Resources, the Wisconsin Department of Natural Resources, and the Minnesota Pollution Control Agency. To date [2001], the partnership that was formed (St. Croix Basin Water Resources Planning Team) has relied heavily on data from NAWQA to implement a protection strategy for the St. Croix River."

-Pam Davis, Coordinator, St. Croix Basin Water Resource Planning Team

\section{NAWOA data are readily available}

The large NAWOA database on national water-quality conditions and other information is accessible over the Internet

(http://water.usgs.gov/nawqa/data) to all interested individuals and organizations. The NAWQA Program encourages use of the national database for a wide range of analyses at national, regional, State, and local scales.

\section{National priority issues}

In collaboration with government, research, and interest-group partners, five water-quality topics have been selected for study on the basis of an extensive analysis of national and regional waterquality issues and priorities. These topical studies will be conducted in those study units most affected by these issues, and which compose a multi-study unit design for systematic national assessment. Each topical study also will address the implications for water-quality management related to, for example, the development of nutrient criteria, source-water protection strategies, or stream restoration plans. The five topics and defining questions are:

\section{Effects of nutrient enrichment on} streams - How do biological communities and associated processes respond to varying levels of nutrient enrichment among agricultural streams in different environmental settings?

Sources, transport, and fate of agricultural chemicals - How do environmental processes and agricultural practices affect the transport and fate of chemicals in the hydrologic systems of nationally important agricultural settings? What are the effects on the quality of streams and ground water?

\section{Transport of contaminants to water supply wells - What are the primary sources and transport mechanisms that affect the occurrence of contaminants in ground water tapped by drinking-water supply wells?}

Effects of urbanization on stream ecosystems-How do stream ecosystems respond to land-use changes associated with urbanization? How do these responses vary across different environmental settings? 


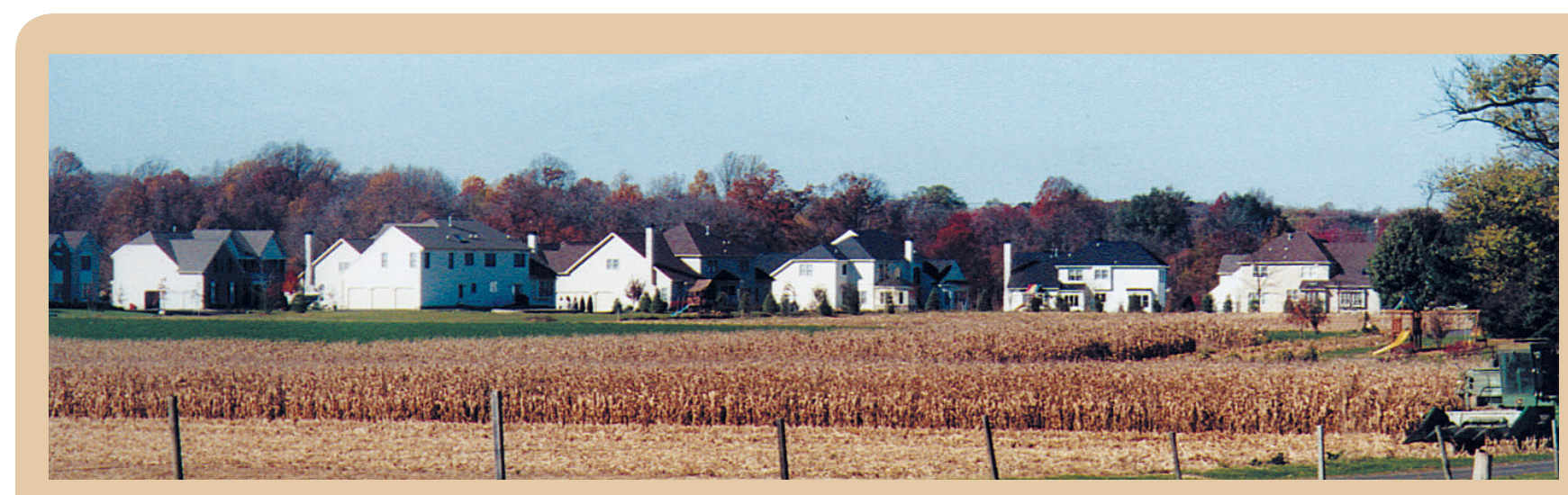

\section{"Urban" focus-Emphasis on recent development}

The NAWQA Program focuses on water-quality impacts from residential and commercial land uses, as well as land-use changes, such as conversion of farmland into low- or high-density development, rather than on what already has occurred in heavily developed urban areas. Water quality within large metropolitan areas and the effects of aging or failing city infrastructure generally are not within the scope of NAWQA.

Bioaccumulation of mercury in aquatic organisms - What are the environmental and biological factors that govern the transformation of mercury into methylmercury, which can accumulate to toxic levels in aquatic food chains?

These five topical studies, which vary in scope and complexity, are the starting point for assessments of priority waterquality issues that will continue throughout the second decade of the NAWQA Program. As the topical studies progress through the three groups of study units, relative emphasis on topics may shift and new topics may be added.

\section{Applying results to unmonitored areas}

Effective strategies for managing contaminants and related water-quality issues require far more information than can be directly measured. Moreover, many management decisions, ranging from budgeting for a management strategy to approving a pesticide for use, are related to the ability to predict potential effects on water quality and aquatic ecosystems. Computer models and other methods are used to apply information from direct measurements of water quality to unmonitored, comparable areas and into the future.

Using the extensive baseline data from the first cycle of studies, NAWQA will increase emphasis on the develop- ment and application of water-quality models for understanding factors that govern water quality and for extrapolation and estimation of future conditions. The NAWQA Program will explore the best methods to predict water-quality conditions based on assessments of landuse and contaminant sources, natural characteristics of the land, and hydrologic transport processes-most commonly as part of the national topical studies.

Equally important to model development is the provision of systematic, high- quality data that can be used by USGS and others to develop and test models for each particular application. Water-quality models have been in use for many years, but their usefulness depends on how well they represent actual conditions. Without demonstrated reliability based on comparisons to measured conditions, model results may not be viewed with confidence, and the usefulness of the model in water-resource management and decision-making, especially in controversial situations, is limited.

\section{Linking quantity, quality, and water use}

NAWQA studies include measurement of streamflow and ground-water levels in conjunction with every chemical and biological sample or measurement. This is important because contaminants and their potential effects on drinking-water supplies and aquatic habitats vary over time and from place to place, largely depending on the amount of water flowing in streams and on the directions of ground-water flow. Similarly, information on surface- and ground-water use is integrated into each assessment. The amount and timing of water use, particularly in areas of extensive irrigated agriculture, large and densely populated urban areas, and recreational areas, can have a profound effect on the quantity and timing of contaminant transport to surface- and ground-water resources.

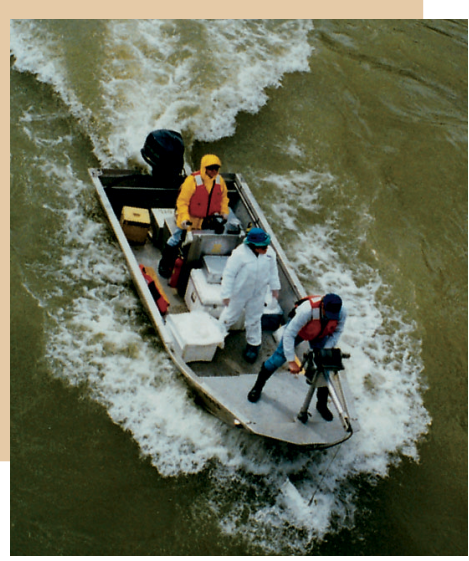




\section{NAWQA study units are reduced and consolidated for the second cycle of assessment}

\section{1 to 2001}

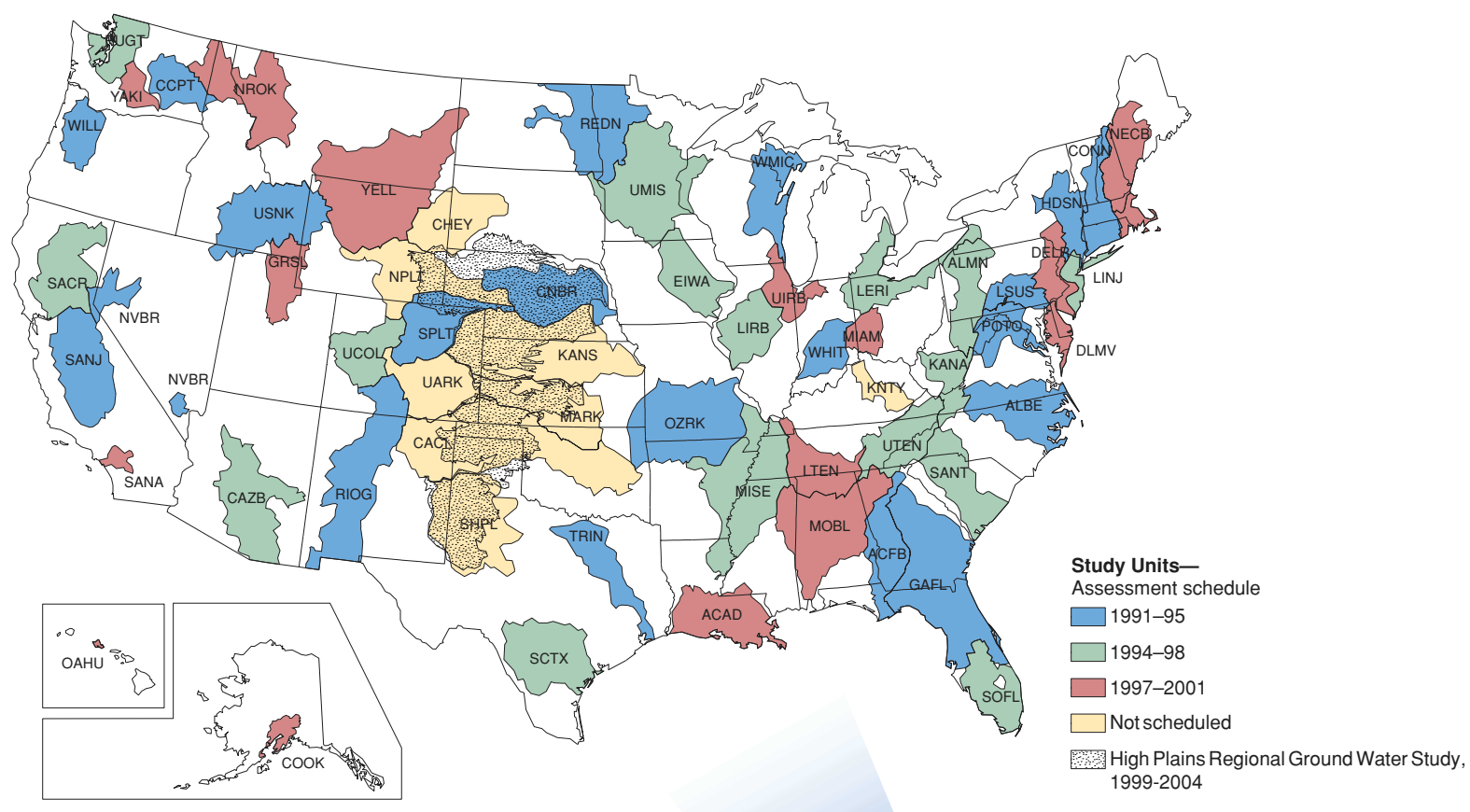

\section{Study units in the second cycle}

In the second cycle of studies, the NAWQA Program will focus on 42 of the Nation's most important river-basin and aquifer systems. The geographic scope of the original design (59 study units) has been adjusted to accommodate budget reductions. A systematic process was used to eliminate 13 study units and combine 8 into 4 study units. Geographic areas were selected to represent a wide range of important hydrologic environments and priority ecological resources; critical contaminant sources, including agricultural, urban, and natural sources; and a high percentage of population served by municipal water supply and irrigated agriculture. The 59 original study units covered about 65 percent of water used for drinking and irrigation; the reduced set of 42 study units still accounts for more than 60 percent of those water uses. This adjusted national study design supports the goal of extrapolating directly measured water-quality conditions to unmonitored, comparable areas in other parts of the Nation.
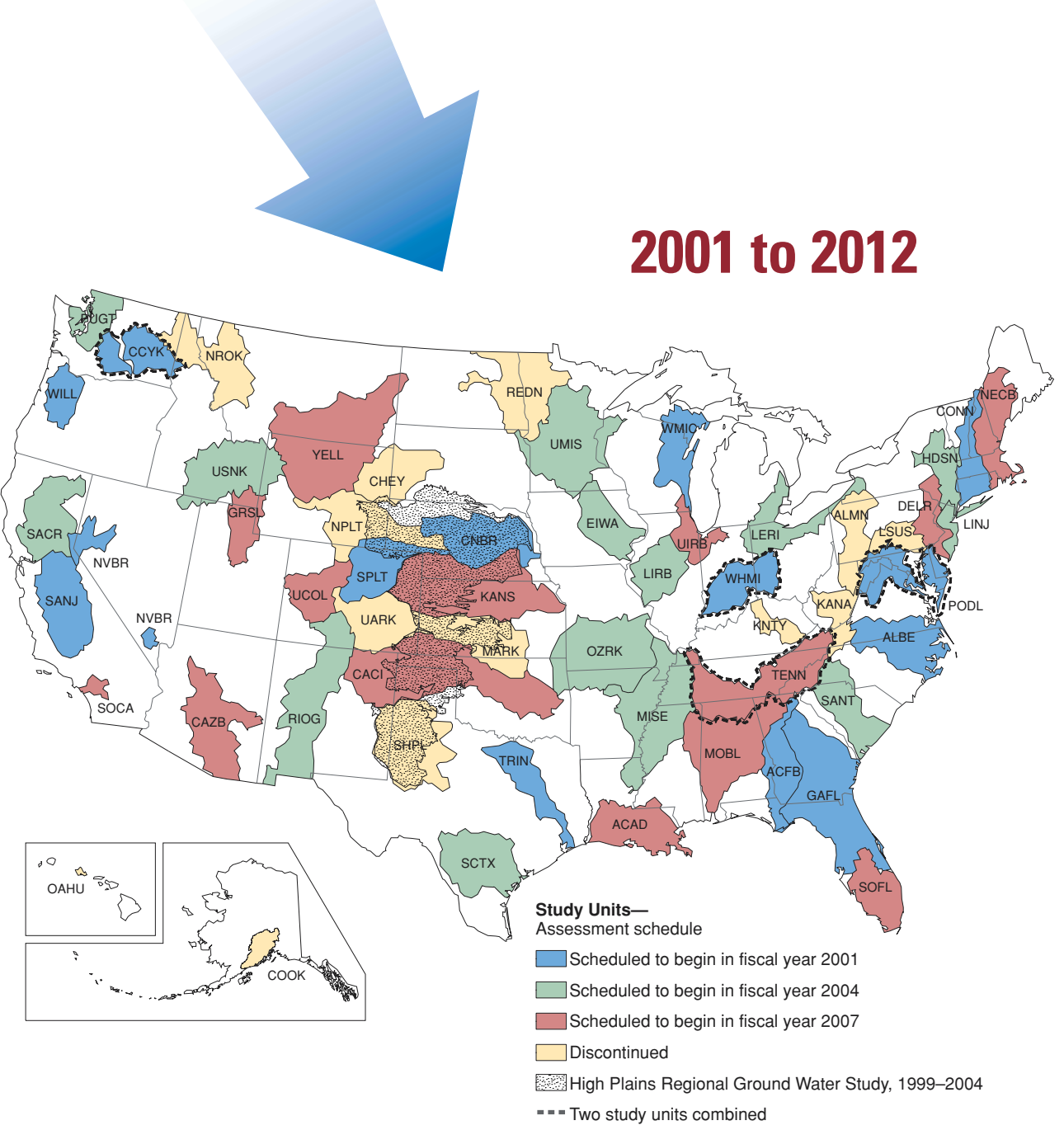
Key to 2001-2012 Study Units

ACAD Acadian-Pontchartrain Drainages

ACFB Apalachicola-Chattahoochee-Flint River Basins

ALBE Albemarle-Pamlico Drainages

$\mathrm{CACl}$ Canadian-Cimarron River Basins

CAZB Central Arizona Basins

CCYK* Central Columbia Plateau (CCPT)-Yakima River Basin (YAKI)

CNBR Central Nebraska Basins

CONN Connecticut, Housatonic, and Thames River Basins

DELR Delaware River Basin

EIWA Eastern lowa Basins

GAFL Georgia-Florida Coastal Plain Drainages

GRSL

HDSN

KANS

LERI

LINJ

LIRB

MISE

MOBL

NECB

NVBR

OZRK

PODL*

PUGT

RIOG

SACR

SANJ

SANT

SCTX

SOCA

SOFL

SPLT

TENN*

TRIN

UCOL

UIRB

UMIS

USNK

YELL

WHMI*

WILL

WMIC

Great Salt Lake Basins

Hudson River Basin

Kansas River Basin

Lake Erie-Lake St. Clair Drainages

Long Island-New Jersey Coastal Drainages

Lower Illinois River Basin

Mississippi Embayment

Mobile River Basin

New England Coastal Basins

Nevada Basin and Range

Ozark Plateaus

Potomac River Basin (POTO) \& Delmarva Peninsula (DLMV)

Puget Sound Drainages

Rio Grande Valley

Sacramento River Basin

San Joaquin-Tulare River Basins

Santee River Basin \& Coastal Drainages

South-Central Texas

Southern California Coastal Drainages

Southern Florida Drainages

South Platte River Basin

Tennessee River Basin (UTEN \& LTEN)

Trinity River Basin

Upper Colorado River Basin

Upper Illinois River Basin

Upper Mississippi River Basin

Upper Snake River Basin

Yellowstone River Basin

White, Great (WHIT) \& Little Miami (MIAM) River Basins

Willamette Basin

* Combination of two study units assessed in the first cycle
Addressing local, regional, and national scales

Each study-unit assessment is guided by a nationally consistent study design and uniform methods of sampling and analysis. The assessments thereby build local knowledge about water-quality issues and trends in a particular stream or aquifer while providing an understanding of how and why water quality varies regionally and nationally. The consistent, multi-scale approach helps to determine if certain types of water-quality issues are isolated or pervasive, and allows direct comparisons of how human activities and natural processes affect water quality and ecological conditions in the Nation's diverse geographic and environmental settings. Comprehensive assessments of pesticides, nutrients, volatile organic compounds, trace metals, and aquatic ecology are developed at the national scale through comparative analysis of study-unit findings.

\section{Study Design}

One-third of all study units are intensively investigated at any given time for 3 to 4 years, and trends are assessed about every 10 years. The second cycle of intensive investigations began again in 14 study units in 2001, all of which had initial intensive assessments during 1991-95. Intensive investigations will be restarted in 14 more study units in 2004 and in another 14 in 2007 (see maps on inside flap). In the meantime, low-level monitoring is maintained. During intensive investigations, high funding levels are allocated to each of the study units to achieve fully integrated and interdisciplinary investigations of the physical, chemical, and biological characteristics of surface- and ground-water resources.

By Robert J. Gilliom, Pixie A. Hamilton, and Timothy L. Miller

Graphic design and layout by Phillip J. Redman

\section{Key to discontinued Study Units}

$\begin{array}{ll}\text { ALMN } & \text { Allegheny-Monongahela River Basins } \\ \text { CHEY } & \text { Cheyenne-Belle Fourche River Basins } \\ \text { COOK } & \text { Cook Inlet Basin } \\ \text { KANA } & \text { Kanawha-New River Basin } \\ \text { KNTY } & \text { Kentucky River Basin } \\ \text { LSUS } & \text { Lower Susquehanna River Basin } \\ \text { MARK } & \text { Middle Arkansas River Basin } \\ \text { NPLT } & \text { North Platte River Basin } \\ \text { NROK } & \text { Northern Rockies Intermontane Basins } \\ \text { OAHU } & \text { Oahu } \\ \text { REDN } & \text { Red River of the North Basin } \\ \text { SHPL } & \text { Southern High Plains } \\ \text { UARK } & \text { Upper Arkansas River Basin }\end{array}$

Visit our Web site at http://water.usgs.gov/nawqa for direct access to reports and other interpretive information, monitoring data, technical reports, and maps.

For additional information, please contact:

Chief, NAWQA Program

(703) 648-5716 (voice)

(703) 648-6693 (fax)

nawqa_info@usgs.gov 